\title{
PICTORIAL ELEMENTS OF INDIAN MINIATURE PAINTING
}

\author{
Dr. K. Mrutyunjaya Rao ${ }^{1 \square}$ (iD
}

${ }^{1}$ Assistant Professor (Sr. Gr), Department of Fine Arts Yogi Vemana University, Kadapa, Andhra Pradesh, India

Received 20 October 2021

Accepted 19 November 2021

Published 20 January 2022

CorrespondingAuthor

Dr. K. Mrutyunjaya Rao,

kotamr@gmail.com

DOI

10.29121/shodhkosh.v3.i1.2022.62

Funding: This research received no specific grant from any funding agency in the public, commercial, or not-for-profit sectors.

Copyright: (C) 2022 The Author(s). This is an open access article distributed under the terms of the Creative Commons Attribution License, which permits unrestricted use, distribution, and reproduction in any medium, provided the original author and source are credited.

\section{ABSTRACT}

This paper discusses the magnificent contribution of Indian miniature painters as the torch bearer of Indian visual culture for the future generations with transitions and various idioms. Its Visual imagery was raised to paramount importance from the religious text to the great tradition of Paintings. Artist has not imitated nature but imbibed the spirit of divinity, greater love, and passion in Indian culture. Its function is religious as well as decorative. "Horrorvacuue" the desire of filling space is the common characteristic of an Indian is often appearing in Indian painting. The articulations of line, colour, space is discussed in this article. The Climatic conditions might have allowed the Indian painter to experience unusual color patterns. The deep-rooted veneration for religion and nature to fulfill the taste of his patron. Which made him a distinct artist in the world forever.

Keywords: Manuscripts, Vishnudharmottara, Metaphysical, “Horror Vacuui, Bhakthi Cult

\section{INTRODUCTION}

The Art of the traditional painting in India is evident from the second century B.C in the form of mural paintings on the walls of Ajanta caves, patronized until the sixth century A.D. From the seventh century onwards, India witnessed many plunders of nomadic Muslim kings, shown with little discrimination, obliterated rich temples and sanctuaries which affected the indigenous religion and art. In result Buddhism waned from India, Jains were not very exemption. In order to save their tradition and religious text to convey to future generations, the priests and monks started to encourage the illustrated manuscript book tradition were to be deposited in the secret places like catacombs or known as Bhandagarhs. This tradition has celebrated its entity from the $9^{\text {th }}$ century A.D to the end of $19^{\text {th }}$ century A.D. through different patrons in different styles and different areas. It was chiefly served for religious purpose, later on for non-religious themes and secular and social events. Although there was no evidence of Hindu manuscripts that produced before fifteenth century, Buddhist sculptures as early as the Gupta period (late Third to fifth century) shows deities holding manuscripts as their attributes, this unfolds that in India, manuscript tradition is antiquated Steven Kossak (1997). The majority of manuscripts dated from eleventh and twelfth centuries were affiliated to Buddhism. 


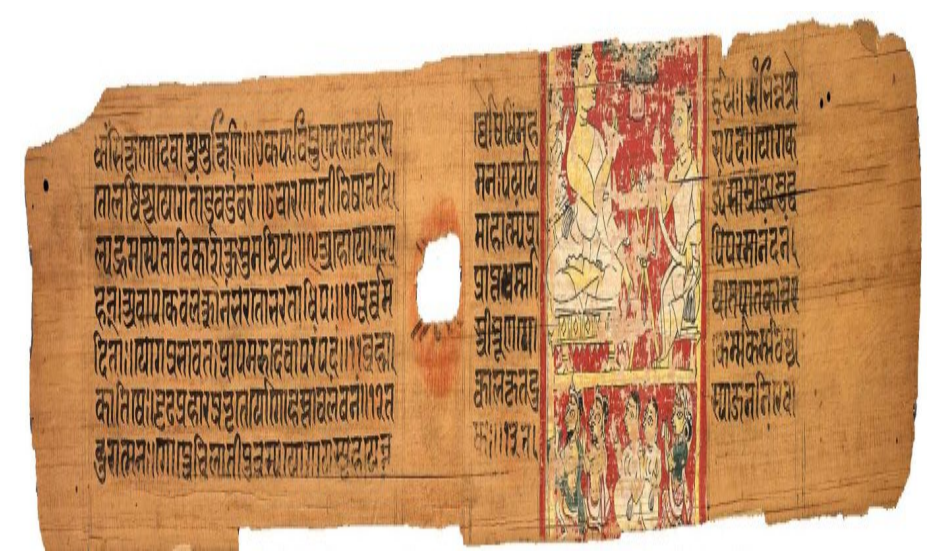

Figure 1 A Folio from an illustrated kalpasutra (Book of Rituals),

Source https://openartimages.com/search/yoga

Palm leaf manuscripts are two feet in length and 2.5 inches in height were made. All these folios were enveloped with the wooden covers. Tiny illustrations were drawn to decorate these with flat colours and bold lines. In earlier times images served as an auxiliary element to the text. These manuscript illustration books were deposited into the religious libraries which were chiefly flourished in western India, largely patronized by rich Jain merchants. Generally, the manuscript page was written first and space left for the illustration, to be painted later. Sometimes the painting and writing were followed at each stage. After the correction of the outline drawing, the surface was covered with thin coat of zinc oxide that fills the pores of the paper and made it as smooth and impervious to the liquid colour. The final drawing was made with the aid of outlines visible through this coating. When the picture was finished, then the reverse side was burnished. The illustrated side was placed on polished marble slab, burnished with agate stone until it gets a mellow glow to the surface. The different colour coatings were applied to the picture one after the other. In every step this burnishing process was repeated. Each colour was allowed to dry completely before the next was applied. The colour coatings were often applied very thin in order to prevent the flaking. An order was followed for the application of colours. At first the fore ground and backgrounds then body colours, clothes, and articles. And finally, out lines were used to emphasis the finishing touches of pearls and ornaments and rendering of the hands, lips, and feet.

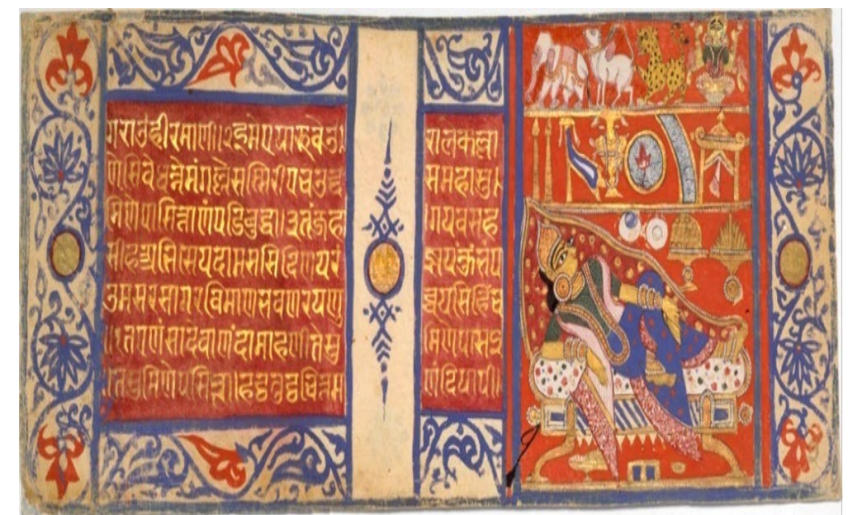

Figure 2 Birth of Mahavira: Folio from a kalpasutra Mansuscript (Gujarat, Jaunpur) 1465 A.D.

Source https://www.metmuseum.org/art/collection/search/37788 
Due to the invention of paper, imported from china and Persia the proportions of the illustration increased with the limited palette and angularity in lines. In later times the format has been changed with multi perspective images and colours blue, gold was used as background colors and details were emphasized with gold, were highly decorated. The important manuscripts are "Kalpa Suthra" and "Kalakacharya katha" and lives of Jain Thirthankaras flourished at various centers such are Mandu, Jaunpur. The same tradition was followed at the courts of sultans at Delhi known as Sultanate painting flourished Mandu, Malwa. The Nimat nama (1500 A.D) known as book of delicacies owes the Persian influence. At the same time Hindu religious text was also illustrated. The romantic poem, Laurchanda (1540 A.D) and Bhagavatha purana and Githa Govinda (1500 A.D) and Maha purana, Adi purana, Bala Gopala stuti were illustrated.

Babur, the Mughal King established his dynasty at Delhi. He had no time to patronize the art of manuscript illustration, but he was well versed with the art of Persia. His son Humayun in his exile at court of Persian king Shah-Tahmasp where he came in to contact with the tinge of art of Persia and artists. While coming back and gaining his throne he brought two Persian masters. They were Mir Syyid Ali, and Abd us Samad to Delhi in 1555A.D. Andrew Topsfield, (1984) Under the direction of these two masters Humayun established art ateliers and employed several local artists. Unfortunately, Humayan could not enjoyed his fruits. After him Akbar ascended the throne as king at the age of thirteen years. In his reign, he encouraged the court painting. Humzanamah (1570) is said to be the earliest manuscript illustration. "Anwer-I-Suhayli (1570 A.D)", "Diwan of Hafiz, Gulistan of Sadi, Tutinama (1580 A.D)" are the important works and Hindu epics were also illustrated "Razam nama". Painting of this period done on cloth as collective work of folios in approximately $67.5 \mathrm{cms} \times 50 \mathrm{cms}$. Painter adopted the advantage of size of the format of the paper size in vertical direction. In terms of composition, the surface was divided into three zones. In 1580 A.D. Akbar received a copy of the polyglot bible illustrated through Jesuit priests. Soon other European paintings and coloured versions of Durer's engravings brought to his court. Due to the influence of European paintings prints, by the order, the painter adopted their technical aspects of European Art. Misikina, Basawan were important artists in those times. The glory of Moghul painting has reached its zenith during the time of Jahangir. Jahangir, in parallel to his father's court. He ran art atelier known as "Salim Studio" Unlike his father, he encouraged the individual painting and artists started to sign on paintings. Painters achieved the perfectness in portraiture and study of botany and birds, animals, "The Death of Inayat Khan" is the best-exemplified portrait and the turkey cock and zebra were famous paintings. The Moghul court painter done secular themes and court life and ordinary scenes.

Contemporary to the Moghuls, the sultans formed their dynasty after the battle of Thallikota in 1565 A.D at Deccan. The painting flourished mainly at three centers, they are Ahamadnagar, Bijapur and Golconda, having the fusion of Persian and Vijayanagara styles. Series of Ragamala paintings, which were given colors to various Ragas and Raginis. Nujum-al- Ulum dated 1570 A.D were important manuscripts. The school of Bijapur was patronized by Adil shahis. Earliest series of Ragamala of this court owes the influence of Turkish and Mongolian art. The Golconda school of painting survived until 1686 A.D. Khawar-nama (1649 A.D), Diwan of Hafiz (1643 A.D) are well known works which has the Mughal influence the Colconda also contributed to the emergence of sub schools in Hyderabad, Sholapur, Cuddapah, Kurnool and Wanaparthy Edith Tomory, (2011). 
During the reign of Aurangzeb, the court painters were dispersed and arrived to the independent states of Hindu kings of Rajasthan. They offered their familiarity with the Moghul idiom, repertoire of subject matter as well as their artistic skills, according to the need of their new patrons. In contrast to Mughals, Rajput art is very subjective, produced based on the metaphysical world, with the influence Bhakthi Cult. Painters took Radha and Krishna as the principal images, and text of Jayadeva's Gita Govinda was given pictorial form, and painted more secular themes, portraits of kings and Queens of Rajasthan. A.K Coomara Swamy the pioneer scholar of Indian art classified the Rajput painting into two categories based upon areas of provenance are as Rajasthan painting, which is from the central plains and the hill side painting is as "Pahari painting". Rajasthani School includes Mewar, Bundi, Kotah, Kishangarh, Bikaner, Jaipur. The Pahari school includes Basholi, Kangra, Guler, Mandu, Jammu etc.

\section{LINE}

The charm of the Indian miniature painting largely rests on the articulation of the sweeping lines. From the Pala to the Kangra tradition and it underwent several phases of transition and attained maturity. The painter cleverly understood the functional characteristics of the line and its articulations on the tiny surface and exploited it to its fullest sense. A sinuous red line, drawn to embellish the shapes of images in Pala tradition owed greater sense of a linear rhythm, which was adopted from the classical Ajanta tradition, executed according to the canons of "Vishnudharmottara". But in contrast to this, the tenth century A.D. Pala painter sought new kind of expression with the use of broken and angular line, but this was not popular as a new style and withdrawn later.

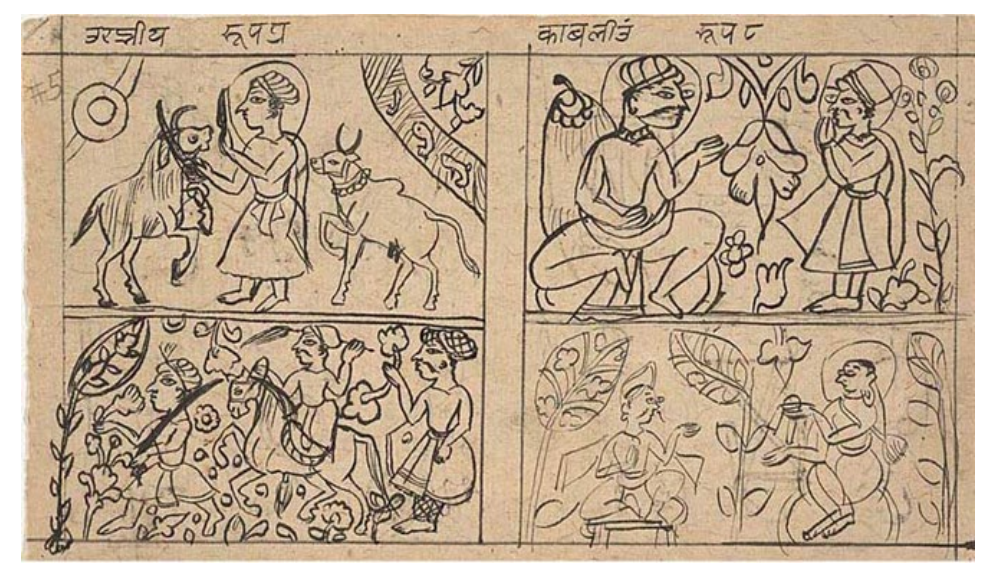

Figure 3 Page from a Dispersed Kalpa Sutra Credits. Metropolitan Museum of Art

Source https://www.metmuseum.org/art/collection/search/38002

The same notions were seen in Jain miniature paintings in fourteenth century. Perhaps the Pala painter might have migrated to the western India to seek patronization from rich merchants. Line in Jain painting is archaic and angular but seems very spontaneous. The painter achieved the relation between calligraphy and the image with the gesticulations in both. Articulations of human figure is executed in bold, broken, and angular lines. The swelling contour of the abdomen seems as emerging from the waist gives the sense of the austerity and spirituality. Unlike the Pala tradition the black line was used to emphasized on contours against the bright red background. Line is very thin, sensuous, bold, and round with little modulations. 
This use of line can separate the image from the surface, moreover each local plane becomes conservative while treating with colour. This angularity has been reduced to some extant in the later period. Then the artist introduced the line which varies in both character and colour.

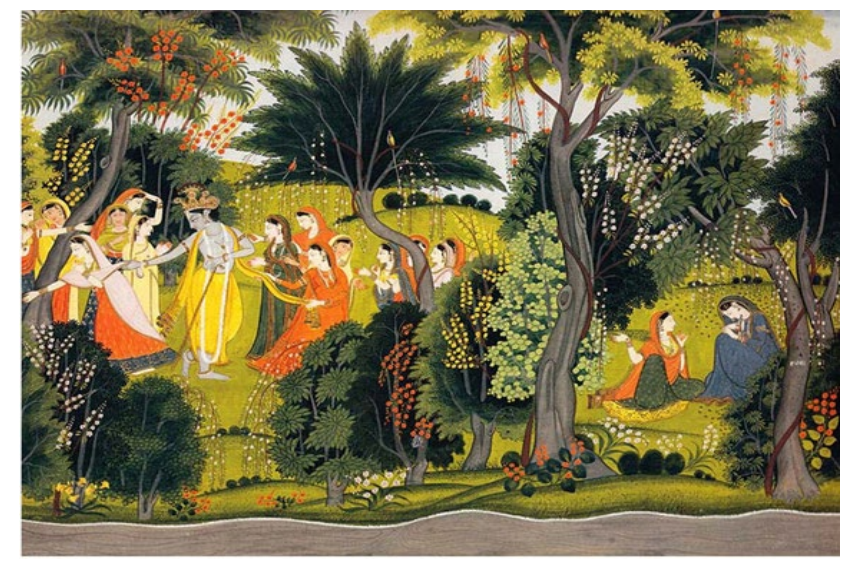

Figure 4 Krishna flirting with Gopis - Kangra Painting, 1760 A.D.

Source https://commons.wikimedia.org/wiki/File:Kangra_Painting.jpg

This angularity might have given the feel of spontaneity a suggestion of volume but appear as rigid evolved as distinct style. The Mughal painter has deserted this style in order to capture the likeness of objects they appeared in front or the immediate surroundings. In Akbar period it attained more dynamism and achieved and ability to capture the psychological character and attempt of the likeness of botany and zoology. In the Zahangir period, the portrait of "The death of Inayat Khan" is the best exemplified for the mentioned earlier. In the painting of "Harivamsa" a thin line is remarkable for draftsmanship reflects the greatness of the Indian painter who drew with a single hairbrush. In the schools of early Rajput, the line was rough and crude in Mewar still angularity is retained a whole it has been exploited to in its use for the appropriate contexts. The rendition of the line to suggest the water varied from each school.

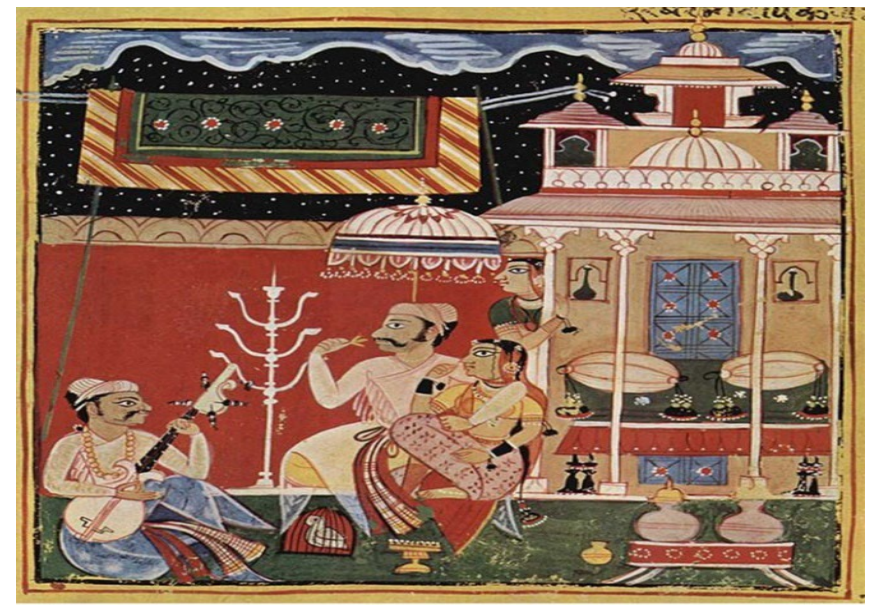

Figure 5 The Ragamala set (Mewar) of 1605 A.D.

Source Chavand Ragamala, The Yorck Project (2002) 
Basket weave patterned lines used in Bhagavatapurana, Adi purana and Maha purana and some Rajasthani schools, tiny lines used for rippling effect of water in Mughal, Bundi and Kotah schools. Moreover, the tiny, stippled line was adopted to Bikaneer school. The dotted, zig- zag line which spills towards the viewer, suggested along the edges of the river is often seen in the Mewar school. In Basholi style, the vertical dotted lines were used to give the sound of the rain. A curved lines suggested in free brush stroke, for sky noticeable in all most all schools and stylized in various manners. The refinement of line reached to pinnacle in Kangra painting where a continuous rhythmic, thin line creates the modulations on the surface of the totality. The elephant was the most recurrently shown animal in miniature tradition. Kotah school artist used thin and curvaceous line for suggesting the fleshy and bony structures. In order to give the decorative quality to the paintings, Indian painter relegated the suggestion of volume and the use of red line give the effect of less projected image from the surface. In order to soften the hard contours of black lines, painter used to place the brown or red line beside the drawn lines. This blend of colour line is called as "optical illusion" which results gives the semblance of volume. The Sweeping and broken lines of Jain miniatures has been refined and reached to the realistic approach in Jahangir times. Rhythm and sweeping curves are refined Kangra paintings.

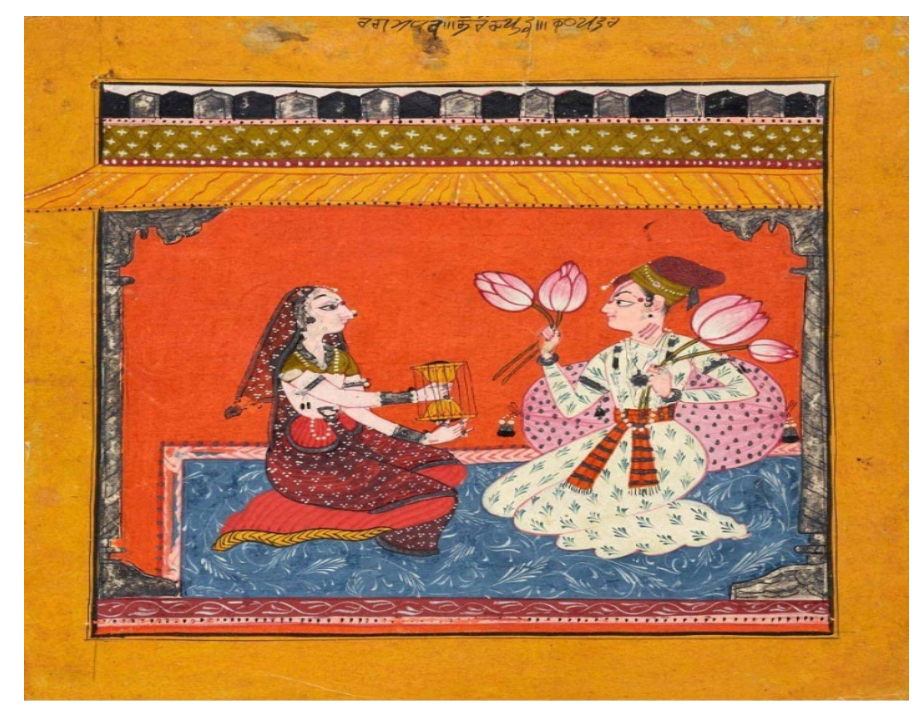

Figure 6 A Folio from Basholi, Pahari School, 16 century A.D.

Source https://rietberg.ch/en/stories/86

\section{COLOUR}

Throughout Indian miniature painting tradition, colour treatment seems not naturalistic but of decorative and it existed as surcharge besides the supremacy of line. The Palette is comprised of multi colours, the combination of complimentary colours such as red and green and blue and orange, yellow, and violet and analogous colours schemes. In general, an Indian can see the bright palette, the choice of colours is personal and the climatic and geographical conditions would play a key role behind the option and depends on the availability of the material too from his immediate surroundings. Painters were proficient in the production of the material before they received the formal training in the art of painting. They had to learn the process and preparation of colour, which process has been discussed. 
In Jain painting, the tiny space might have allowed the painter for the flat application of colour against the strong contours in the black line. Besides the availability of the red pigment, perhaps the traditional symbolism, magical quality; it has been associated in the traditions of subsequent years with great sensibility. On the other hand, the red colour has fewer wavelengths than any colour. So, it can be perceived earlier than the any other colour. The black line against the red surface gives a shimmering effect more over due to the climatic conditions of specific regions also allows to perceive those strange and strong combinations.

The Indian tropical situation, human eye allows seeing the things lucidly. Perhaps, it could be the reason for the choice bright palette by the Indian painter than any other in the world. The later times, the availability of lapis lazuli and gold enriched the palette. In order to give quality and sense of decorativeness, that artist relegated the of use of broken colours, this may be termed as colour abstraction. It is noticed in Basholi and Guler schools. The capturing of strong sunlight would reflect in Basholi paintings as strong yellows and background in Guler school panting was depicted as strong red patches. From my observation the brownish red tones of the hill-areas might been rendered in pure reds in order to obtain the decorative quality.

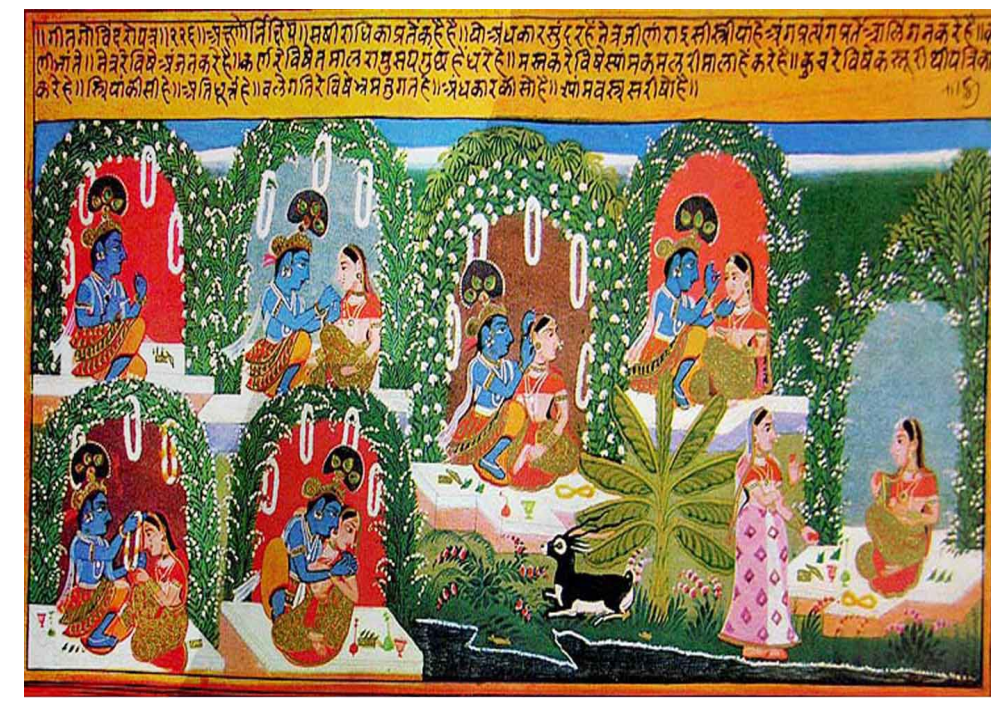

Figure 7 Narration of Gita Govinda of Mewar

Source https://www.exoticindiaart.com/

The repetition of colour in Mewar School is predominant. To narrate the story, figuration has been used in repetition; in addition to this the colour also played a pivotal role. Throughout the tradition of miniature painting, the image of Krishna always painted in blue complexion with yellow robes. Here yellow stands for auspicious, knowledge and blue symbolize the sky or spirituality. Throughout the Rajput painting this repetition of colour was strictly followed for the image of Krishna. It is a trait to universalize both the colour and image of Krishna. From the psychological aspects repetition creates strong registration on the human mind, as which we come across in daily life in the form of advertisements. Perhaps this was culled from the contemporary folk theatre of those times. Because in earlier times the long narrations need two to three persons were used for a single role for the continuity thought night in that drama In Mewar painting it served as the basis for the division of the space. 


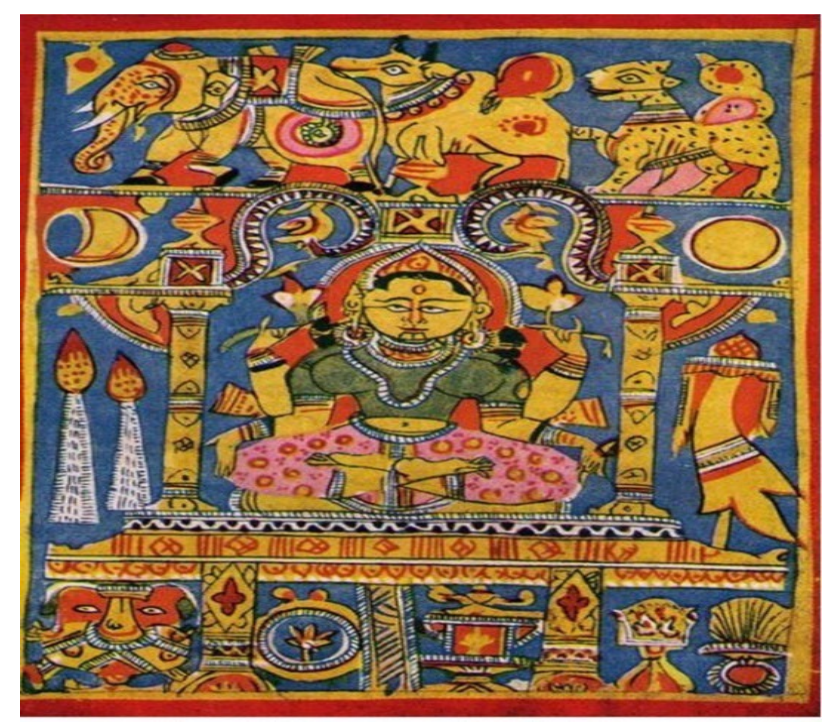

Figure 8 Dreams of Trishala

Source

\section{SPACE}

The term "space" technically can be defined as the opened areas between the objects arrange on the surface. The height and the width and depth characterize it. In painting, space is illusionistic by means of interplay of lines and colours at the surface level. In the earlier times the third dimension doesn't go much beyond than what it was need.

The miniature painter might not be aware of technical words as of this modern era. But his sense of judgment, aesthetic sensibility while dealing surface was purely depended on his visual experience as rather than the text for some time. The availability of limited material had restricted to articulation of space in painting. Earlier, it was a tiny square was allotted to the painter on palm leaf manuscripts. There one can notice the figuration laden on the surface, successively attains the compartment and horizontal tiers of the composition.

After the introduction of the paper, the composition is varied but the format remains the same. As the time passes, the painter gave emphasis to his artistic traits, as a result, the image was predominant in the manuscript illustration. Then the descriptive text was thrown to the upper sections of the composition. In the time of the Mughals, their interest in Persian flavour and its influence is shown on the compositions, which is a vertical direction, the horizontal line was fixed at the upper level, due to this the foreground was given more emphasis and loaded with objects interconnected to the story as well as their immediate surroundings. In the Rajput painting we notice a shift to the horizontal format from the vertical format of Mughal painter. The space can be better understood from Jain miniatures, the characteristics such are the profile face with protruding eye, frontal torso and the presence of the images put in various proportions, placement of colours of closure intensities would create the feeling of complexity to the beholder and suggest the illusion of the shallow space, but harmonious and aesthetic. In his sense of depiction of a protruding eye, seems just attached to the tree-fourths of the profile would reveal the enquiry about the space. It is understood that the painter was very fond of showing an object comprehensively. The entire space has no clear and sharp 
divisions but filled with different images at various horizontal levels in multi-tier composition. This tendency of filling objects seems increased further, appears more in the Mandu Kalpasutra of 1439 A.D. In Jaunpur Kalpasuthra 1447 A.D and 1465 A.D and in 'Devasano pada Bhandara" manuscripts too it is seen. The empty areas were filled with tiny decorative elements emphasized with gold which makes the surface and decorative and more visually attentive. This tendency of filling space can be called as "horror vacui' which appears as the chief characteristics of Indian painting. In the folio of Humza Nama, one can notice that the architectural settings, bathing pools and carpets with high qualitative organic motives are shown in three dimensional views as if we are watching from a height or a bird view. The plane of foreground appears as if it is just tilted towards the beholder. This mode of representation allows the painter to distribute the pictorial elements across the surface as if they are spilling towards spectator. The appearance of total composition seems distributed by making division by the walls, in the process of revealing the articulation of all the participants in the whole drama. It is a kind of common chrematistics that is looking into the others activity or life. The figuration shown in profile views relegated the foreshortening. This characteristic feature is brought as a continuous element in both the Mughal and Rajput painting. It is hypothecated that this choice was very functional and technical. The profile of an image unfolds the character, emphasis on the personality, especially beauty of women. Technically the contours of the face or body creates the rhythmic sensations on the area which known as the space. The protuberance and depressions create a tension in the space around it. The combination of the two different dimensions is put together with partial overlapping. This can be noticed even when two of the group are shown. This creates short distance, and some appears as cut and paste work against the three zones such as foreground, middle ground and background of which the surface is divided.

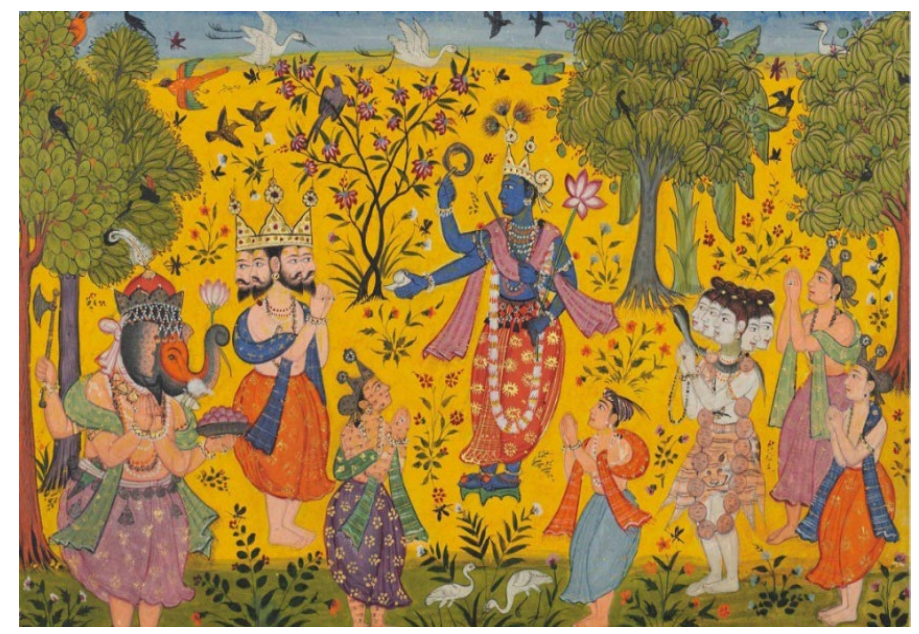

Figure 9 An Illustration from Ragamala Series from Imperial mugul, 1610 A.D.

Source https://www.christies.com/features/Collecting-guide-Classical-Indian-Painting-7378-

1.aspx

The work of the Mughal period, besides its adoptions of European elements which ushered Indian painter towards the rendition of the optical perspective the suggestion of deep space can be seen in the painting of "Seize of Ranathambur". The reduced size of images was placed at the upper corner of the composition, then the 
images rendered at the foreground. The diagonal compositions of armies across the surface creates motion into a particular direction. In the early paintings of the Hindu text, Bhagavata purana of 1550 A.D. and "Gita Govinda" of 1580 A.D., space has been suggested with several planes.

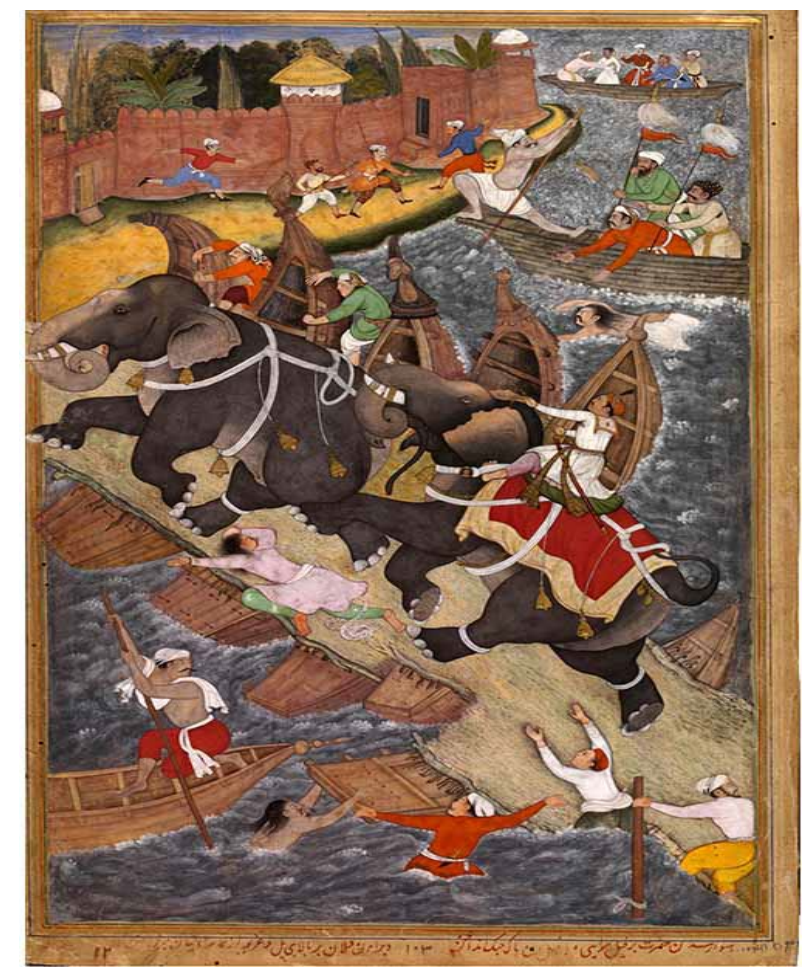

Figure 10 Seize of Ranathambur, Akbar Period 1618 A.D.

Source

The Mewar school "Gita Govinda" of early $17^{\text {th }}$ century A.D. would be the best exemplified school of Rajasthani painting. The throwback of religious influence besides the experiments is widely noticed. The picture space should be read as was determined in terms of celestial and terrestrial space. The surface was often divided in to four to five zones, suggests the passage of time and seasons and land and heaven in single composition. Unlike the other earlier works the special zone of sky and water were radically placed wherever required. The use of multiple perspective had played pivotal role while coordinates those zones. It is noticed that all these objects are drawn from various perspectives and put together on the surface. In result, we found several vanishing points within a single plane. This unsychronization creates the compactness and irrationality in space. Sometimes the heavenly image exists with the mundane world. Its semblance is surrealistic. In the process of depicting synthesis of both celestial and terrestrial world, Indian painted had used a reverse perspective along with the conventional depiction of images. In the three manuscripts of 'Gita Govinda', landscape and sky are always depicted in the reverse perspective views, this means the imaginative perspective lines seems to diverge towards the horizontal line. The focal point of vanishing lines was fixed in front of the viewer. The tree which is closure to viewer seems smaller than the far one. The phenomenon of several vanishing points is also taken from the Ajanta murals. This also known as multiple perspective depiction. 


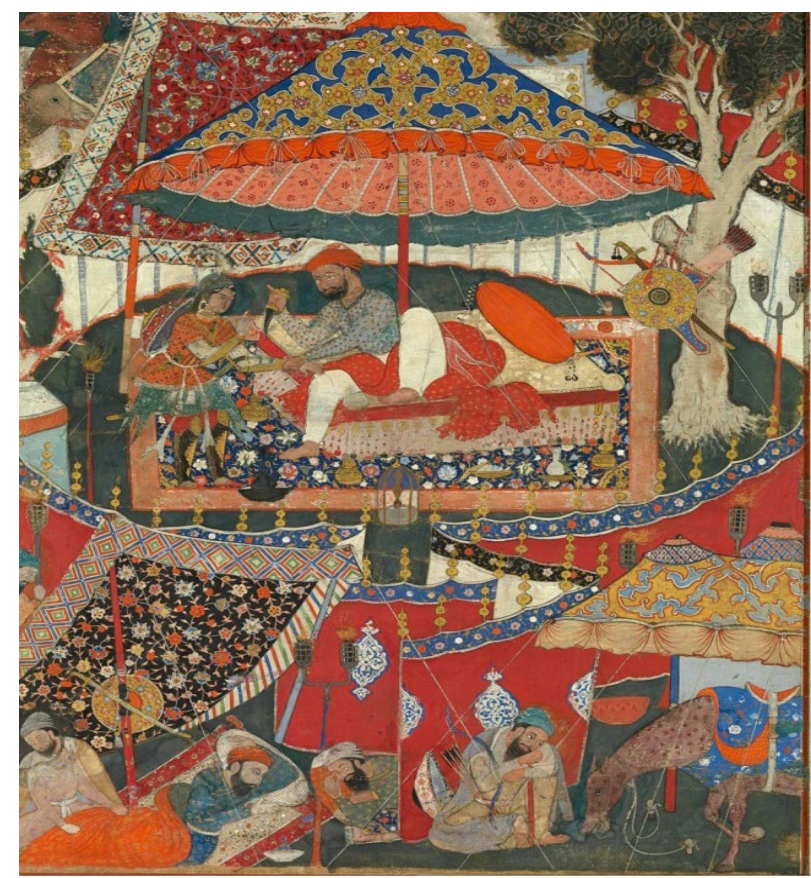

Figure 11 A Folio from Humzanama, 1560 A.D.

Source https://artsandculture.google.com/asset/a-page-of-the-dastan-i-amir-hamzahamzanama-mughal/rgG3VJ1dVK78-w

\section{CONCLUSION}

The Miniature painting tradition has emerged as a result of Muslim destruction and restrictions. From the mural scale, small scale was served as the auxiliary element to the religious text in its early articulations, but subsequently due to its extensive visual vocabulary and their manipulation, it possessed the primary rank and threw the text to the upper registers of the painting. The Indian painters were diligent in converting their communications with nature into the pictorial languages. It is understood the concept for the Indian painting is both functional and decorative. A deep-rooted preoccupation and love with nature took concrete form within the parameters of the availability of the material. The nature he possessed through the air he breathed and water he drunk and the land where he lived were the accentuating factors to his creative potential. "Horrorvacuue" the desire of filling space is the common characteristics of an Indian. It is reflecting in our lives for example the desire of an average Indian woman for draping sari with strong colours and the large bold pattern. The Climatic conditions might be allowed the Indian painter to experience such unusual colour patterns. The deep-rooted veneration for religion and nature and to fulfil the taste of his patron and society and passion with figuration, Indian painter had appropriated the decorative quality with technical perfection and openness to adopt the elements of other cultures is made him as a distinct artist in the world forever.

\section{REFRENCES}

Andrew, T, (1984). Indian Court Painting, Mumbai,
https://doi.org/10.2134/jeq1984.133441x. 
Pictorial Elements of Indian Miniature Painting

Edith, T, (2011). A History of Fine Arts in India and the West Orient Black Swan Pvt.Ltd, Hyderabad, 256.

Steven, K. (1997). Indian Court Painting, New York, 6. 